\title{
2D $\mathrm{SnS}_{2}$ Nanostructure-Derived Photocatalytic Degradation of Organic Pollutants Under Visible Light
} Rohit Ranjan Srivastava ${ }^{1}$, Pramod Kumar Vishwakarma ${ }^{2}$, Umakant Yadav ${ }^{3}$, Suyash Rai ${ }^{1}$,
Sima Umrao ${ }^{4}$, Rajiv Giri ${ }^{2}$, Preeti Suman Saxena ${ }^{3}$ and Anchal Srivastava ${ }^{*}$

${ }^{1}$ Department of Physics, Institute of Science, Banaras Hindu University, Varanasi, India, ${ }^{2}$ Center of Materials Science, University of Allahabad, Prayagraj, India, ${ }^{3}$ Department of Zoology, Institute of Science, Banaras Hindu University, Varanasi, India, ${ }^{4}$ Department of Physics, Indian Institute of Science, Bangalore, India

Wastewater produced by the textile industry contains various dyes and organic compounds that directly or indirectly affect surface water or groundwater pollution. Visible-light-driven semiconductor photocatalysis is the leading pathway for the degradation of environmental pollutants. Herein we report the bottom-up hydrothermal growth of 2D tin disulfide nanostructures $\left(\mathrm{SnS}_{2} \mathrm{NSs}\right)$ for the efficient photodegradation of organic pollutants such as Rhodamine B (Rh.B) and Methyl Violet (M.V) in an aqueous medium under visible light $(\lambda>400 \mathrm{~nm})$ irradiation. The as-synthesized $\mathrm{SnS}_{2} \mathrm{NSs}$ were characterized by various structural, morphological, and optical techniques such as XRD, RAMAN, TEM, UV-Vis, Brunauer-Emmett-Teller, etc. Furthermore, the low bandgap $(\sim 1.6 \mathrm{eV})$, the high surface area $\left(56 \mathrm{~m}^{2} / \mathrm{g}\right)$, and the anionic nature of $\mathrm{SnS}_{2} \mathrm{NSs}$ attribute to it as an efficient photocatalyst for photocatalytic applications. The photocatalytic properties of $\mathrm{SnS}_{2} \mathrm{NSs}$ showed good degradation efficiency of 94 and $99.6 \%$ for Rh. $\mathrm{B}$ and M.V, respectively, in $25 \mathrm{~min}$. The kinetic rate constant of these dyes was estimated by using the Langmuir-Hinshelwood model. Here we also performed the recyclability test of the photocatalyst and discussed the plausible mechanism for the photocatalytic degradation of organic pollutants. The XPS spectra of $\mathrm{SnS}_{2} \mathrm{NSs}$ were studied before and after the photodegradation of Rh.B and M.V, indicating the high stability of the photocatalyst. Moreover, in vitro cytotoxicity was also evaluated against human cervical cancer cell lines (HeLa cells) with different concentrations $(0-1,000 \mu \mathrm{g} / \mathrm{ml})$ of assynthesized $\mathrm{SnS}_{2}$ NSs. This intended work provides a possible treatment for the degradation of organic pollutants under visible light to balance the aquatic ecosystems.

Keywords: semiconductor photocatalyst, 2D $\mathrm{SnS}_{2}$ NSs, hydrothermal growth, photocatalytic degradation, organic dyes

Received: 18 May 2021

Accepted: 29 July 2021

Published: 23 August 2021

Citation:

Srivastava RR, Kumar Vishwakarma $P$,

Yadav U, Rai $S$, Umrao S, Giri R, Saxena PS and Srivastava A (2021) 2D

$\mathrm{SnS}_{2}$ Nanostructure-Derived Photocatalytic Degradation of Organic

Pollutants Under Visible Light.

Front. Nanotechnol. 3:711368

doi: 10.3389/fnano.2021.711368

\section{INTRODUCTION}

The efficient disposal of environmental pollutants is one of the major problems, of which water pollution is the prime concern. Due to the rapid growth of industrial activity, chemical fertilizers and raw sewage have a direct or indirect impact on surface water or groundwater pollution (Schwarzenbach et al., 2010; Li et al., 2020a; Li et al., 2021). Commercially, over 100,000 dyes are available, and 700,000 tonnes are produced each year (Robinson et al., 2001). Among other pollutants, organic pollutants are becoming a major source of environmental contamination. 


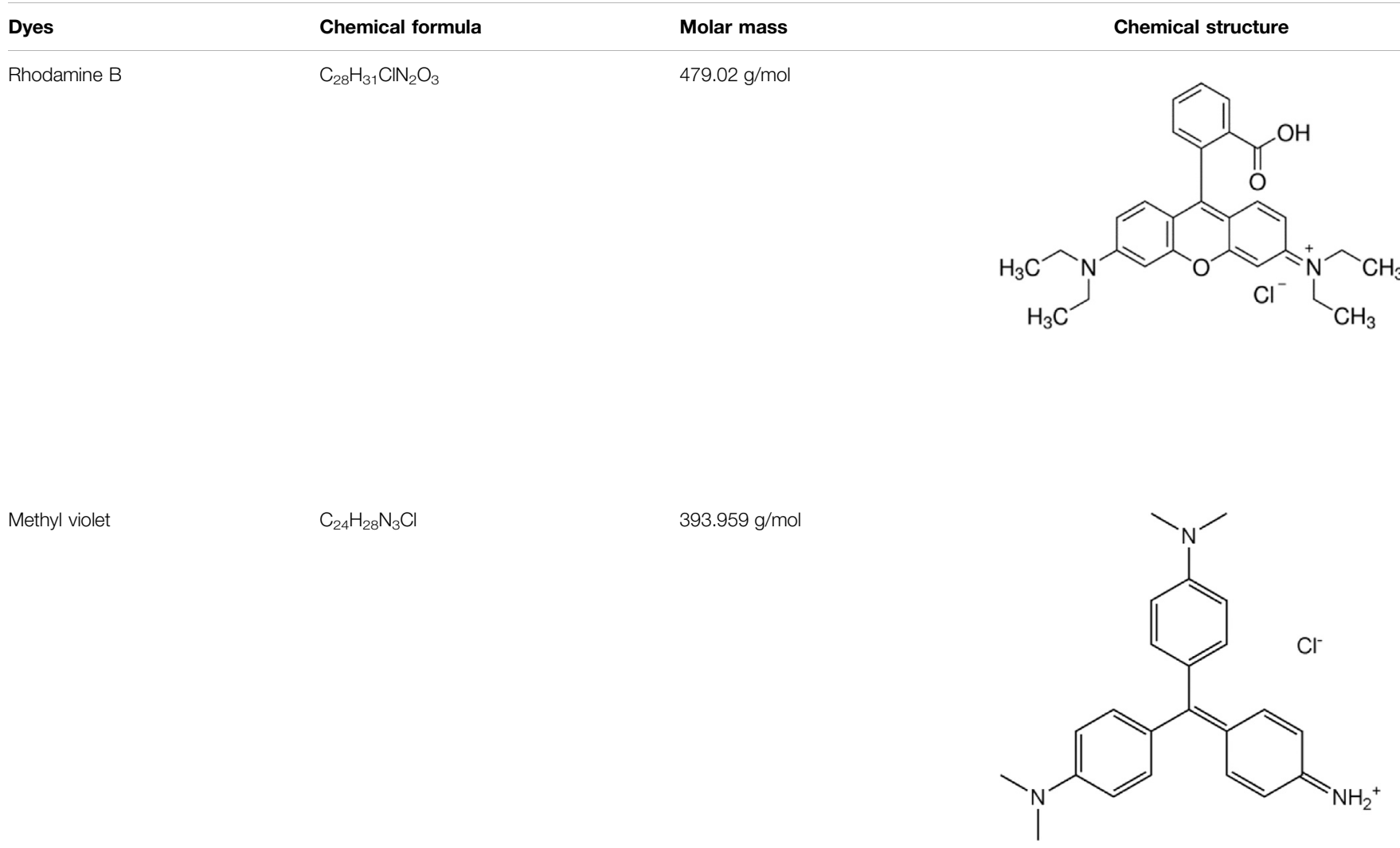

Organic dyes are widely used in various industrial fields such as the leather industry, food, plastics, cosmetics, coloring agent in textile, and many more (Xie et al., 2000; Brillas and MartínezHuitle, 2015). Approximately $10-20 \%$ of organic dyes that originate as wastewater from industries affect the balance of aquatic ecosystems. Organic dyes are toxic, mutagenic, carcinogenic, have disobedient molecules, and have low biodegradability (Xie et al.). To reduce the organic contaminants from wastewater, various methods have been adopted, such as ozonization, carbon adsorption, flocculation, and activated sludge process which is very tedious, unable to remove organic pollutants, requires expansive tools, and can also lead to secondary pollution (Patll and Shinde, 1988; Stock et al., 2000; Kim et al., 2016). However, to overcome these limitations, the photocatalytic degradation process is an effective and authentic technique that can be used to remove organic pollutants in the aqueous medium. In this process, the photocatalyst converts toxic organic dyes into nontoxic intermediates under ultraviolet or visible light irradiation (Zhong et al., 2009; Li et al., 2019).

In the last few years, semiconductor-based photocatalyst has been extensively used as an alternative to the degradation and decolorization of organic dyes. The semiconductor-based photocatalysts show tremendous properties such as high surface area, high charge transfer, active abundant site, a tunable optical band gap, and many more (Talebian and Nilforoushan, 2010; Opoku et al., 2017; Li et al., 2020b). In this context, various semiconductor-based photocatalysts such as $\mathrm{SnO}_{2}, \mathrm{ZnO}, \mathrm{TiO}_{2}$, etc., have gained wide attention among the scientific community due to their excellent catalytic properties which require only the inexhaustible solar spectrum as the driving force for conducting the catalytic response (Cao et al., 2015; Sharma et al., 2017; Singh et al., 2017). However, the major disadvantage of these photocatalysts are high bandgap, less active sites, less low availability (3-5\%) of UV light, and negotiated quantum efficiency (Štengl et al., 2013). Therefore, to overcome these limitations, the development of a novel photocatalyst with high absorption capacity and which can reduce bandgap is highly needed.

In the last few years, the semiconducting metal sulfide photocatalysts have attracted much attention among researchers due to their tremendous properties, such as lightabsorbing ability in visible and near-field regions, high surface area, and abundant active surface sites (Guo et al., 2010; Xie et al., 2010; Zhang et al., 2011; Tian et al., 2017). Recently, in the IV-VI group semiconductors, tin disulfides $\left(\mathrm{SnS}_{2}\right)$ have engrossed much consideration due to their strong anisotropic optical property in various potential applications, such as in electrical switching, solar cell, and catalytic reactions (Zhang et al., 2011a; Du et al., 2013; Song et al., 2013). $\mathrm{SnS}_{2}$ is an n-type semiconducting material with the general formula $\mathrm{MX}_{2}$ (where $\mathrm{M}$ stands for metal atom Sn, Mo, and $\mathrm{W}$, and $\mathrm{X}$ stands for chalcogen atom $\mathrm{S}$, $\mathrm{Se}$, and $\mathrm{Te}$ ) which belongs to the two-dimensional-layered metal dichalcogenides family. Structurally, $\mathrm{SnS}_{2}$ has a hexagonal $\mathrm{CdI}_{2}$ type crystal structure in which one layer of $\mathrm{Sn}$ atom has been sandwiched between two layers of S atom via in-plane covalent 

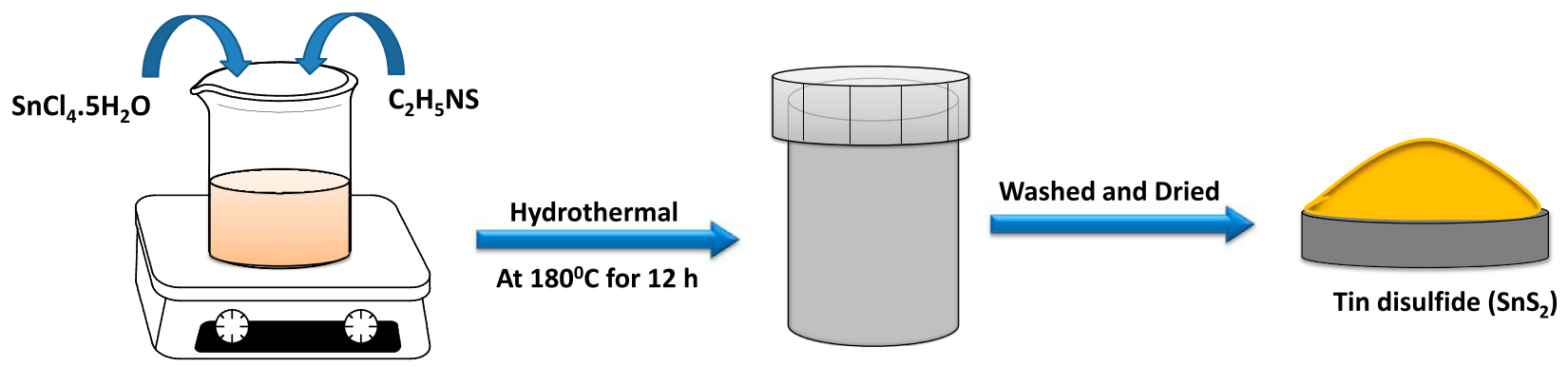

SCHEME 1 | Schematic illustration for the hydrothermal synthesis of $\mathrm{SnS}_{2} \mathrm{NSs}$.

bonding and has weak van der Waals force between the adjacent layers. $\mathrm{SnS}_{2}$ has been widely used in various technological applications, such as sensors, energy storage, photodetectors, solar cell, and many more (Tan et al., 2011; Umar et al., 2013; Su et al., 2015; Srivastava et al., 2019). Moreover, tin disulfide is earth-abundant, cost-effective, has high carrier mobility, has a large surface active site, less toxic, and chemically stable in both acidic and neutral conditions, which make them a promising material for the degradation of organic pollutants (Li et al., 2012a; Umar et al., 2013; Lorenz et al., 2014). To date, various $2 \mathrm{D} \mathrm{SnS}_{2}$-based nanostructures have been reported for photocatalytic application (Li et al., 2012b; Umar et al., 2013; Balu et al., 2018). However, all these methods have low degradation efficiency and were covered with inorganic materials or any organic surfactant molecules which restrict any interaction on their material surface and corresponds to a reduced catalytic activity. Therefore, it is of utmost importance to develop a novel photocatalyst which has abundant active sites, is biocompatible, has lower toxicity, and has a wider spectral response for the degradation of organic pollutants.

Therefore, in the present investigation, we report the synthesis of $\mathrm{SnS}_{2} \mathrm{NSs}$ using a facile one-pot bottom-up ecofriendly hydrothermal method without a subsequent surface treatment. The as-synthesized $\mathrm{SnS}_{2}$ NSs show a low bandgap, a high surface area, and an anionic character. Furthermore, it has been observed that the degradation efficiency of organic dyes such as Rh.B and M.V is $\sim 94$ and $\sim 99.6 \%$, respectively, using $\mathrm{SnS}_{2} \mathrm{NSs}$ as a photocatalyst under visible light in $25 \mathrm{~min}$. The recyclability test and underneath detailed degradation mechanism were also discussed in the present work. Here we also estimated the in vitro cytotoxicity against human cervical cancer cell line (HeLa cells) with various concentrations of as-synthesized $\mathrm{SnS}_{2} \mathrm{NSs}$.

\section{EXPERIMENTAL TECHNIQUES}

\section{Materials}

Tin (IV) chloride pentahydrate $\left(\mathrm{SnCl}_{4} \cdot 5 \mathrm{H}_{2} \mathrm{O}\right)$ and methyl violet were purchased from Molychem, India. Thioacetamide $\left(\mathrm{C}_{2} \mathrm{H}_{5} \mathrm{NS}\right)$ was purchased from OTTO Chemical, India. Rhodamine $\mathrm{B}$ and methyl violet were purchased from HIMEDIA, India. The human cervical cancer cell line (HeLa cells) was procured from the National Centre for Cell Sciences, Pune, India. The culture medium (RPMI-1640), fetal bovine serum, antibiotics, trypsin, and EDTA solutions were procured from Sigma Aldrich. The dimethyl sulphoxide (DMSO) was purchased from SRL Chemicals. Distilled water was used in the present work. All chemicals were used without any decontamination and were of analytical grade.

The molecular weight and chemical structure of organic dyes (such as Rhodamine B and Methyl Violet) used in the present work is shown above.

\section{Hydrothermal Synthesis of $\mathrm{SnS}_{2}$ Nanostructures}

Scheme 1 shows the schematic of the one-pot bottom-up hydrothermal synthesis of $\mathrm{SnS}_{2} \mathrm{NSs}$. $\mathrm{SnCl}_{4} \cdot 5 \mathrm{H}_{2} \mathrm{O}$ and $\mathrm{C}_{2} \mathrm{H}_{5} \mathrm{NS}$ were used as the starting precursor of Tin $\left(\mathrm{Sn}^{+4}\right)$ and sulfur $\left(\mathrm{S}^{-2}\right)$ sources, respectively, for the growth of $\mathrm{SnS}_{2} \mathrm{NSs}$. In the typical reaction process, $\mathrm{SnCl}_{4} \cdot 5 \mathrm{H}_{2} \mathrm{O}(\sim 1.8 \mathrm{~g})$ and $\mathrm{C}_{2} \mathrm{H}_{5} \mathrm{NS}(\sim 1.6 \mathrm{~g})$ were completely dissolved in $60 \mathrm{ml}$ of distilled water and vigorously stirred for $120 \mathrm{~min}$ at room temperature. Afterward, the complete solution was transferred in a Teflon-lined autoclave at $180^{\circ} \mathrm{C}$ for $12 \mathrm{~h}$. After the proposed reaction time, the autoclave is allowed to cool down at room temperature. A yellowish color solution was obtained, which was further washed several times with distilled water, and the sample was finally dried in vacuum at $80^{\circ} \mathrm{C}$ for $6 \mathrm{~h}$.

\section{Synthesis Reaction}

During the hydrothermal synthesis, the hydrolysis of thioacetaamide produced ammonium acetate $\left(\mathrm{CH}_{3} \mathrm{CO}_{2} \mathrm{NH}_{4}\right)$ and hydrogen sulfide $\left(\mathrm{H}_{2} \mathrm{~S}\right)$ as products. The reaction between $\mathrm{Sn}^{+4}$ and $\mathrm{H}_{2} \mathrm{~S}$ produced a yellow color perception which is responsible for $\mathrm{SnS}_{2}$ NSs. The possible reactions for the formation of $\mathrm{SnS}_{2} \mathrm{NSs}$ are shown by Eqs. 1, 2 as follows (Zhang et al., 2011a):

$$
\begin{gathered}
\mathrm{C}_{2} \mathrm{H}_{5} \mathrm{NS}+2 \mathrm{H}_{2} \mathrm{O} \rightarrow \mathrm{CH}_{3}-\mathrm{CO}-\mathrm{NH}_{4}+\mathrm{H}_{2} \mathrm{~S} \\
\mathrm{Sn}^{+4}+\mathrm{H}_{2} \mathrm{~S} \rightarrow \mathrm{SnS}_{2}+4 \mathrm{H}^{+}
\end{gathered}
$$

The obtained powder was then further characterized in detail and used as an efficient photocatalyst for the photocatalytic degradation of Rh.B and M.V.

\section{Instruments Used for Characterization}

The morphology and the structure of as-synthesized $\mathrm{SnS}_{2} \mathrm{NSs}$ were examined using a transmission electron microscope (TEM, 
A

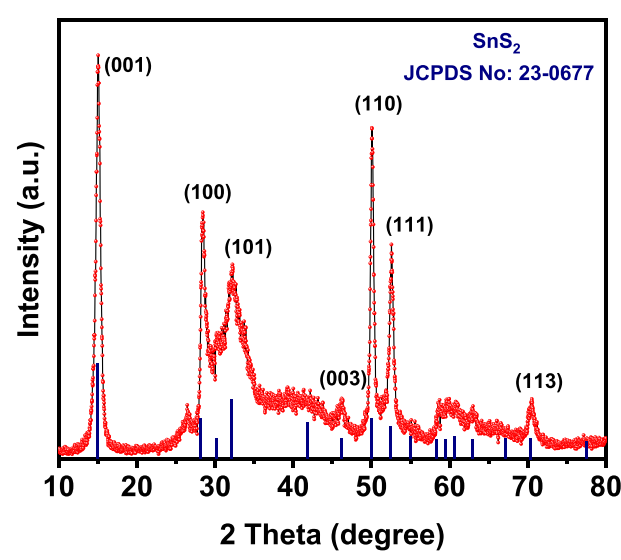

C

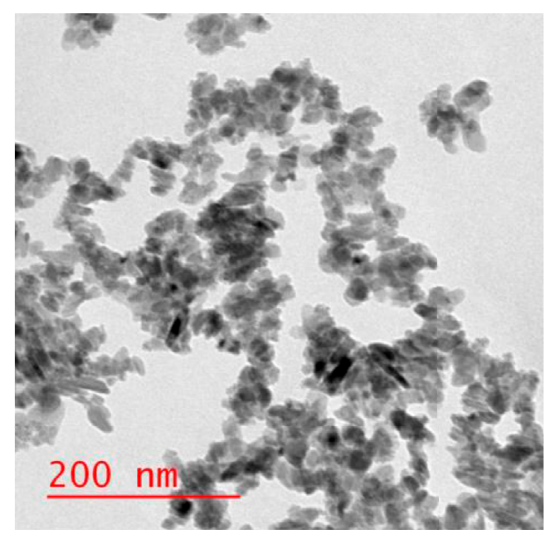

$\mathbf{E}$

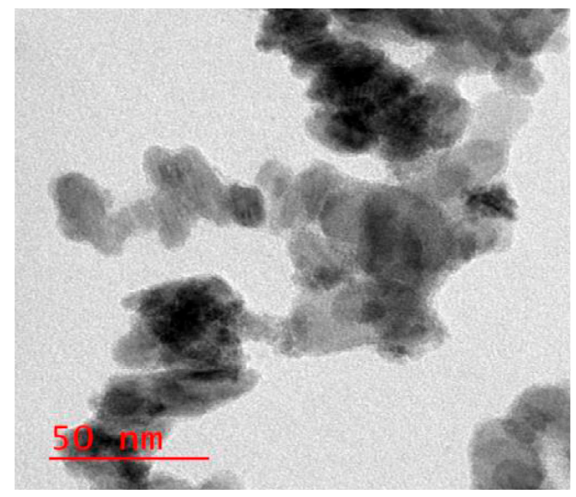

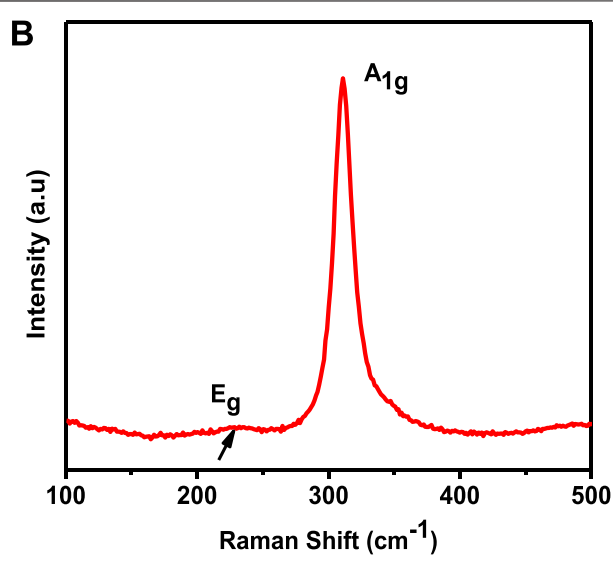

D

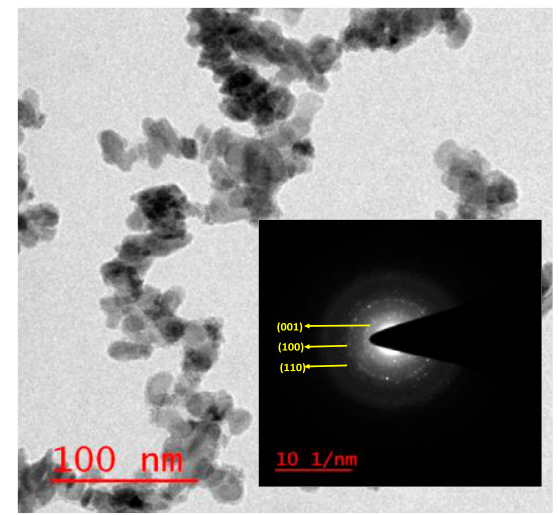

$\mathbf{F}$

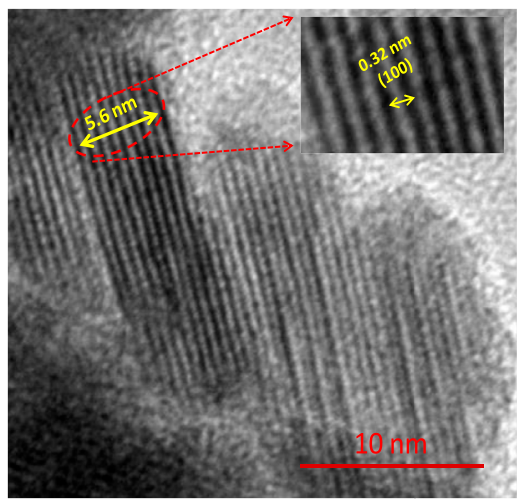

FIGURE 1 | (A) X-ray diffraction pattern of $\mathrm{SnS}_{2}$ NSs. (B) RAMAN spectra of $\mathrm{SnS}_{2} \mathrm{NSs}$. (C-F) Transmission electron microscope and high-resolution transmission electron microscope images of as-synthesized $\mathrm{SnS}_{2} \mathrm{NSs}$ with different magnification levels.

FEI-Technai $G^{2}$ F20, United States) with an accelerating voltage of $200 \mathrm{kV}$. The crystal phase and the crystallinity were examined by an X-ray diffractometer (PANalytical, United Kingdom) using $\mathrm{Cu}-\mathrm{Ka}$ radiation $(\alpha=1.54178 \AA)$ at a scanning rate of $1^{\circ} \mathrm{s}$, ranging from $10^{\circ}$ to $80^{\circ}$. Raman spectrophotometer (Renishaw, United Kingdom) was used to analyze the structural and the phase purities of as-synthesized $\mathrm{SnS}_{2}$ NSs. Fourier transform infrared (FTIR) spectrometer (Frontier, Perkin Elmer, United States) was used to determine the functional group. Total organic carbon (TOC) was measured using Lotix TOC Analyzer. The specific surface area was measured by Gemini VII 2390 surface area analyzer (Micromeritics, United States). All the photocatalytic activity of dyes was performed by using a UV-Vis spectrometer (UV-1800 SHIMADZU, Japan). X-ray photoelectron spectroscopy (XPS) was analyzed using PHI Versa Probe III.

\section{Cell Culture and Cell Viability}

Human cervical cancer cell line (HeLa cells) was cultured and maintained under a controlled atmospheric temperature at $37^{\circ} \mathrm{C}$ under $5 \% \mathrm{CO}_{2}$ in RPMI-1640 medium, supplemented with $10 \%$ fetal bovine serum, penicillin $\left(100 \mathrm{U} \mathrm{ml}^{-1}\right)$, and streptomycin $\left(100 \mathrm{mg} \mathrm{ml}^{-1}\right)$. The 3-dimethylthiazol-2,5-diphenyltetrazolium bromide (MTT) assay was performed to evaluate cell viability after $24 \mathrm{~h}$ of cell seeding in the presence or absence of $\mathrm{SnS}_{2} \mathrm{NSs}$. In 

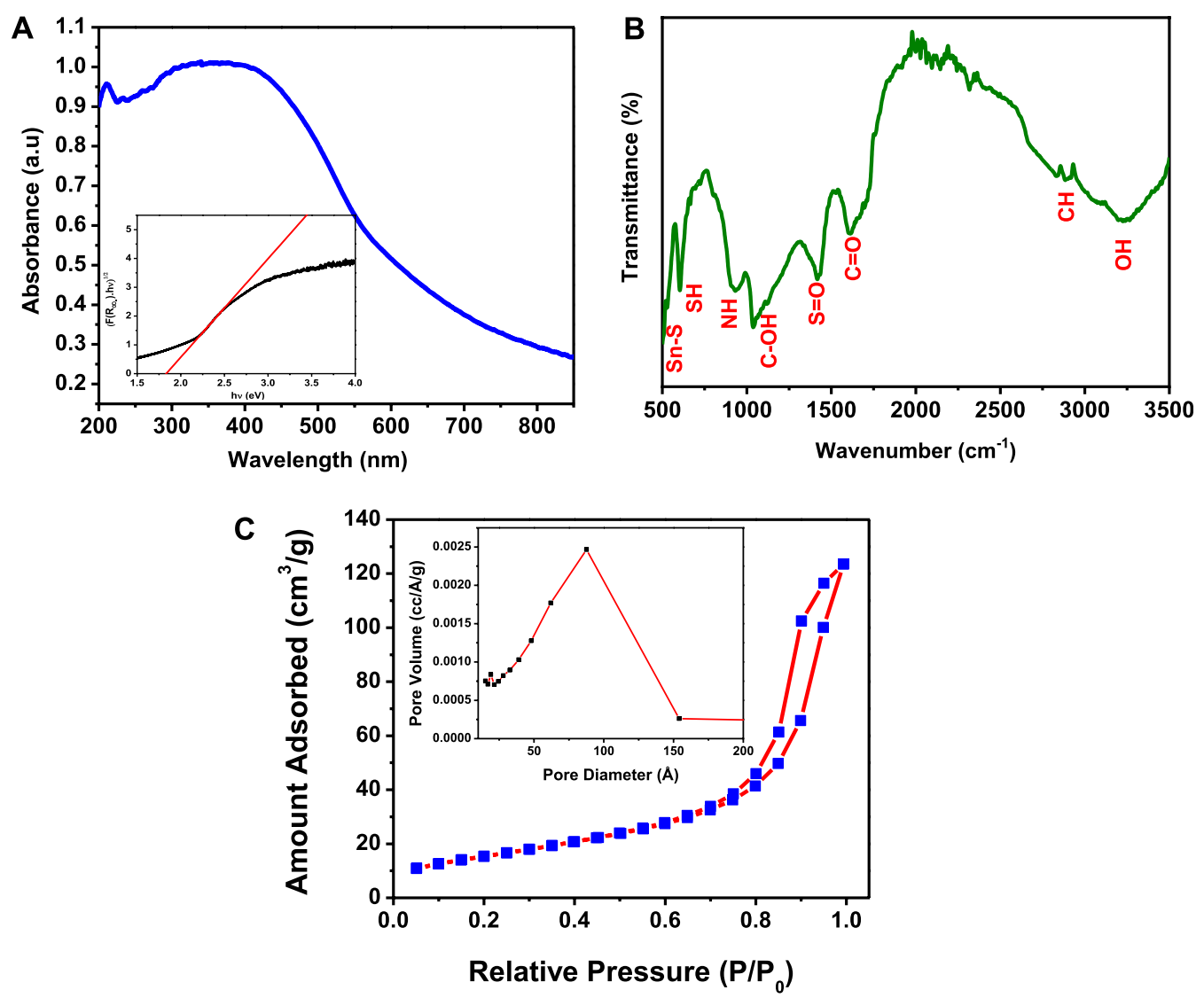

FIGURE 2 | (A) Absorbance spectra. (B) Fourier transform infrared spectra. (C) Surface area measurements of $\mathrm{SnS}_{2}$ using the $\mathrm{N}_{2}$ adsorption-desorption isotherms and Brunauer-Emmett-Teller analysis.

brief, HeLa cells were seeded in a 96-well polystyrene plate (TCP), with a density of $1 \times 104$ cells per well, and incubated under controlled conditions $\left(5 \% \mathrm{CO}_{2}, 37^{\circ} \mathrm{C}\right)$ for $24 \mathrm{~h}$. After that, the cells were treated with different concentrations $(1.562,3.125,6.255$, $12.5,25,50,100,200,400,800$, and $1,000 \mu \mathrm{g} / \mathrm{ml})$ of SnS $_{2}$ NSs and incubated for $24 \mathrm{~h}$ at $37^{\circ} \mathrm{C}$. After that, the cells were incubated with MTT solution $(0.5 \mathrm{mg} / \mathrm{ml}$ in culture medium $)$ at $37^{\circ} \mathrm{C}$ for $4 \mathrm{~h}$ and allowed formazan crystal formation. After incubation, the supernatant was removed, and $200 \mu \mathrm{l}$ of DMSO was added and incubated for $30 \mathrm{~min}$ at $37^{\circ} \mathrm{C}$. After the complete dissolution of formazan crystals, the optical density of the solution was measured at $540 \mathrm{~nm}$ by a microplate reader (PerkinElmer Victor 4 microplate reader). The wells without $\mathrm{SnS}_{2}$ NSs were used as controls. The values were expressed as mean \pm standard deviation $(n=3)$. Cell viability was calculated using the following equation:

Cell viability $(\%)=[$ Abs $]$ test $/[$ Abs $]$ control $\times 100$

\section{Sample Preparation for the Photocatalytic Activity of Dyes Using $\mathrm{SnS}_{2}$ NSs}

The photocatalytic activities of the synthesized $\mathrm{SnS}_{2}$ NSs were evaluated by investigating the photodegradation of Rh.B and M.V under visible light radiation. The stock solution of $100 \mathrm{ml}$, with the concentration of $10 \mathrm{mg} / \mathrm{L}(10 \mathrm{ppm})$ of Rh.B and M.V, was prepared and stored in a dark room. A fluorescent lamp of $40 \mathrm{~W}$ $(\lambda>420 \mathrm{~nm})$, with a radiation intensity of $0.79 \mathrm{~W} / \mathrm{m}^{2}$, was used for the light source. The volume of the initial solution $(10 \mathrm{ml})$ of Rh.B and M.V was taken out for further photocatalytic activity. For the photocatalytic experiments, $5 \mathrm{mg}$ of $\mathrm{SnS}_{2} \mathrm{NSs}$ was added to $10 \mathrm{ppm}$ solution of M.V and Rh.B and stirred for $5 \mathrm{~min}$ from the initial phase of the solution. The decomposed dyes of the different solutions were measured by using a UV spectrometer after regular time intervals. The concentration of aqueous M.V and Rh.B was determined by measuring its absorbance value, ranging from 400 to $800 \mathrm{~nm}$, using a UV spectrophotometer. Furthermore, the detailed photodegradation study of M.V and $\mathrm{Rh} . \mathrm{B}$ is also discussed in the present work.

\section{RESULT AND DISCUSSIONS}

\section{Structural and Morphological Characterizations of $\mathbf{S n S}_{\mathbf{2}} \mathbf{N S s}$}

The as-synthesized $\mathrm{SnS}_{2}$ NSs are well characterized in terms of their structural, morphological, and optical properties. Powder X-Ray diffraction has been performed to determine the crystallinity and the crystal phase of as-synthesized $\mathrm{SnS}_{2} \mathrm{NSs}$, as shown in Figure 1A. The characteristic diffraction peaks observed at $15.0^{\circ}, 28.1^{\circ}, 32.1^{\circ}, 46.1^{\circ}, 50.1^{\circ}, 52.4^{\circ}$, and $70.3^{\circ}$ 


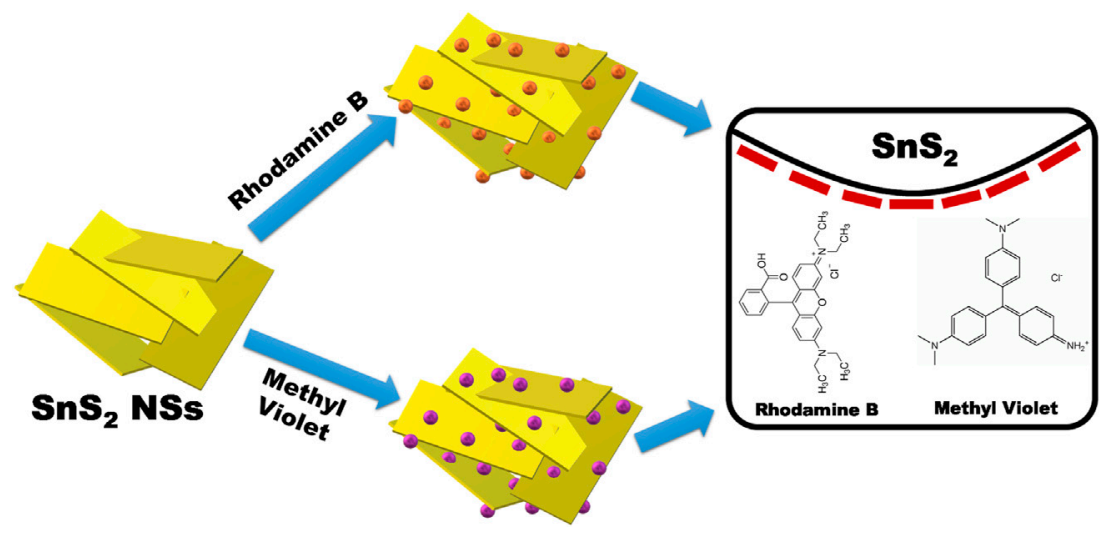

SCHEME 2 | Schematic illustration of the interaction between cationic dyes with anionic $\mathrm{SnS}_{2} \mathrm{NSs}_{\text {. }}$

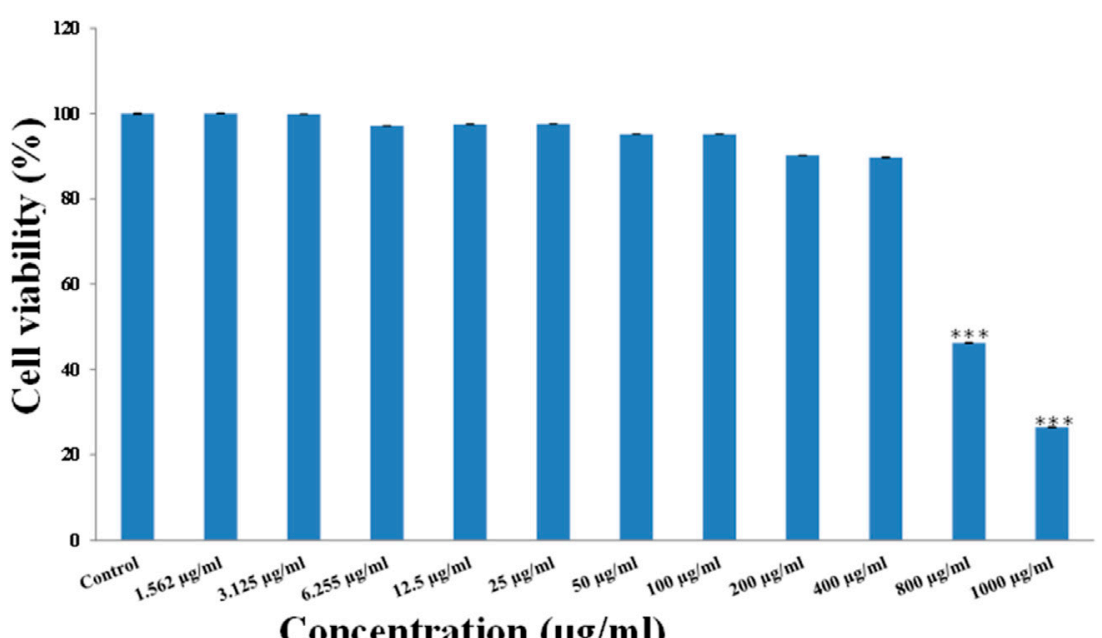

FIGURE 3 | In vitro cell compatibility with different concentrations of $\mathrm{SnS}_{2} \mathrm{NSs}$.

correspond to planes (001), (100), (101), (003), (110), (111), and (113), respectively.

The observed XRD pattern of $\mathrm{SnS}_{2}$ NSs is well suited with JCPDPS card no. 22-0677, which suggests the hexagonal phase of $\mathrm{SnS}_{2}$ with lattice constant $a=3.649 \AA$ and $c=5.899 \AA$ and having space group: P-3m1 (164). The average crystallite size of assynthesized materials was calculated by the Debye-Scherer formula which is given below:

$$
D=\frac{K \lambda}{\beta \cos \theta}
$$

where $K$ represents the shape factor, $\beta$ represents the broadening of the diffraction line at half-maximum intensity (radians), and $\theta$ represents Bragg's angle. The average crystallite size of $\mathrm{SnS}_{2} \mathrm{NSs}$ was estimated to be $\sim 30 \mathrm{~nm}$ from the Scherer formula.

RAMAN is a versatile and non-destructive technique to evaluate the structural and vibrational properties of nanomaterials. The RAMAN spectra of as-synthesized $\mathrm{SnS}_{2}$ NSs were recorded with a laser excitation source of $532 \mathrm{~nm}$, as shown in Figure 1B. There are two characteristic peaks located at
224 and $310 \mathrm{~cm}^{-1}$, which correspond to $E_{\mathrm{g}}$ (in-plane vibrational mode) and $A_{1 \mathrm{~g}}$ (out-of-plane vibrational mode) modes, respectively (Deepika Bharatula et al., 2016).

The size and the morphology of as-synthesized $\mathrm{SnS}_{2}$ NSs were determined by TEM, as shown in Figures 1C-F. A typical highresolution transmission electron microscope image of $\mathrm{SnS}_{2}$ is shown in Figure 1F. The morphology of as-synthesized $\mathrm{SnS}_{2}$ was found to be nanostructures in nature. The interlayer spacing of assynthesized $\mathrm{SnS}_{2} \mathrm{NSs}$ is $0.32 \mathrm{~nm}$, which corresponds to the (100) crystalline plane, as shown in the inset of Figure 1 F (Umar et al.).

\section{Photophysical Characterization and Specific Surface Area Measurements of $\mathrm{SnS}_{2}$ NSs}

The photophysical property of as-synthesized $\mathrm{SnS}_{2}$ NSs was estimated by UV-Vis diffuse reflectance spectra and FTIR. The absorption spectrum of $\mathrm{SnS}_{2}$ NSs was recorded in the wavelength range of $200-800 \mathrm{~nm}$, as shown in Figure 2A. The broad absorption spectrum in the visible region indicates that 

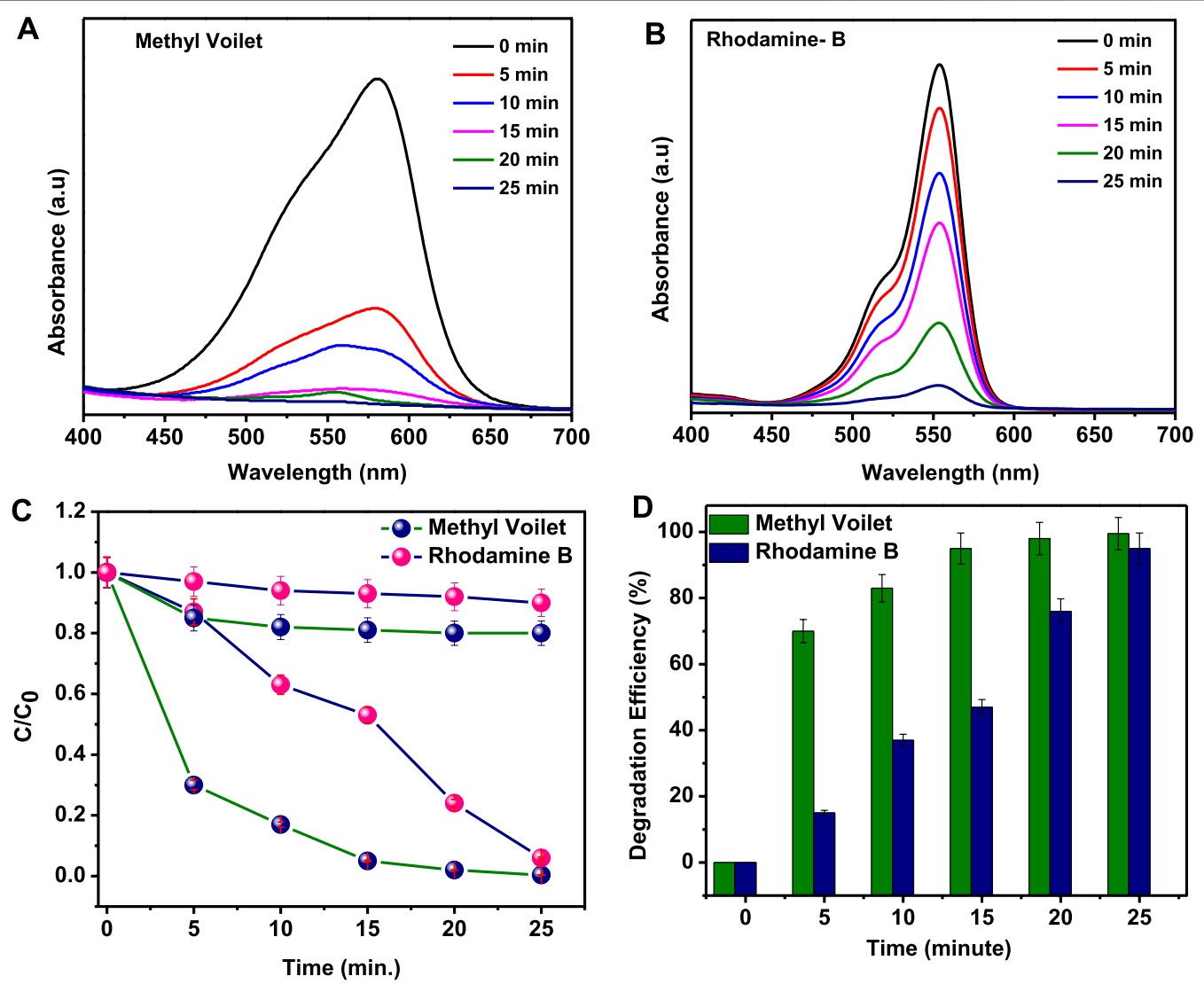

FIGURE 4 | (A,B) Absorption spectra of the degradation of methyl violet and Rhodamine B, respectively, under visible light irradiation. (C) Relative concentration of decomposed dye. (D) Degradation efficiency (in \%).

the as-synthesized $\mathrm{SnS}_{2}$ NSs are capable of harvesting visible light and act as an efficient photocatalyst for photocatalytic reactions under a visible regime. The optical energy bandgap of as-synthesized $\mathrm{SnS}_{2}$ NSs was determined by the band edge absorption relation as follows:

$$
(\alpha h \vartheta)^{1 / n}=B\left(h \vartheta-E_{g}\right)
$$

where $E_{\mathrm{g}}$ is the optical energy bandgap, $B$ is the optical-transitiondependent constant, $\vartheta$ is the frequency of the incident beam, $n$ characterizes the transition $(n=2$ for allowed transition and $n=3$ for forbidden transition), and $h$ is the Planck's constant. Here the absorption coefficient $(\boldsymbol{\alpha})$ was determined by the Kubelka-Munk function for estimating the absorption edge energy. So, the curves of $\left[\mathrm{F}\left(\mathrm{R}_{\infty}\right) \mathrm{hv}\right]^{1 / 2}$ vs. (hv) for $\mathrm{SnS}_{2} \mathrm{NSs}$ are plotted in the inset of Figure 2A (Zhang et al., 2011b). The bandgap of as-synthesized $\mathrm{SnS}_{2}$ NSs was calculated to be $1.6 \mathrm{eV}$. The lower bandgap indicates the visible-light-driven photocatalytic activity.

FTIR was performed to determine the function group over the surface of as-synthesized $\mathrm{SnS}_{2}$ NSs. In Figure 2B, the FTIR spectrum of $\mathrm{SnS}^{2} \mathrm{NSs}$ was recorded, ranging from 400 to $4,000 \mathrm{~cm}^{-1}$. The peaks located at 3,226, 2,907, 1,610, 1,414, $1,194,934,612$, and $545 \mathrm{~cm}^{-1}$ correspond to $-\mathrm{OH},-\mathrm{CH}, \mathrm{C}=\mathrm{O}$, $-\mathrm{S}=\mathrm{O},-\mathrm{C}-\mathrm{OH}, \mathrm{N}-\mathrm{H}, \mathrm{C}-\mathrm{H}$, and $\mathrm{Sn}-\mathrm{S}$, respectively. The presence of functional groups such as $-\mathrm{OH},-\mathrm{COOH}$, and $\mathrm{S}=\mathrm{O}$ may be responsible for making the $\mathrm{SnS}_{2}$ NSs anionic or negatively charged. This could lead to $\mathrm{SnS}_{2}$ as a promising material for the removal of cationic organic contaminants in an aqueous solution. Furthermore, electrostatic adsorption might be the prime factor for the interaction of selectively positive charged dyes such as Rh.B and M.V with negatively charged $\mathrm{SnS}_{2}$ (Han et al., 2017). Hence, $\mathrm{SnS}_{2}$ could be the superior adsorbent for industrial dyes, especially cationic dyes such as Rh.B and M.V, as shown in Scheme 2.

For photocatalytic applications, the designing of materials with a high surface area plays a crucial role in providing abundant active sites. This leads to the diffusion of dye molecules and enhancing the adsorption capability during the dye degradation process (Zhu et al., 2013; Han et al., 2017). In the present work, $\mathrm{N}_{2}$ adsorption-desorption isotherms and the corresponding Barratt-Joyner-Halenda (BJH) adsorption curve have been performed over $\mathrm{SnS}_{2} \mathrm{NSs}$, as shown in Figure 2C. The pore size of as-synthesized $\mathrm{SnS}_{2}$ NSs has been estimated by using the $\mathrm{BJH}$ method. This suggests that the pore size of $\mathrm{SnS}_{2}$ NSs varies from 5.5 to $16 \mathrm{~nm}$, as shown in the inset of Figure 2C. The Brunauer-Emmett-Teller analysis suggests that the surface area of as-synthesized $\mathrm{SnS}_{2} \mathrm{NSs}$ is $56.6 \mathrm{~m}^{2} / \mathrm{g}$, with pore volume of $0.184 \mathrm{cc} / \mathrm{g}$ and average pore width of $10 \mathrm{~nm}$. This measurement reveals that the as-synthesized $\mathrm{SnS}_{2} \mathrm{NSs}$ possess a high surface area 

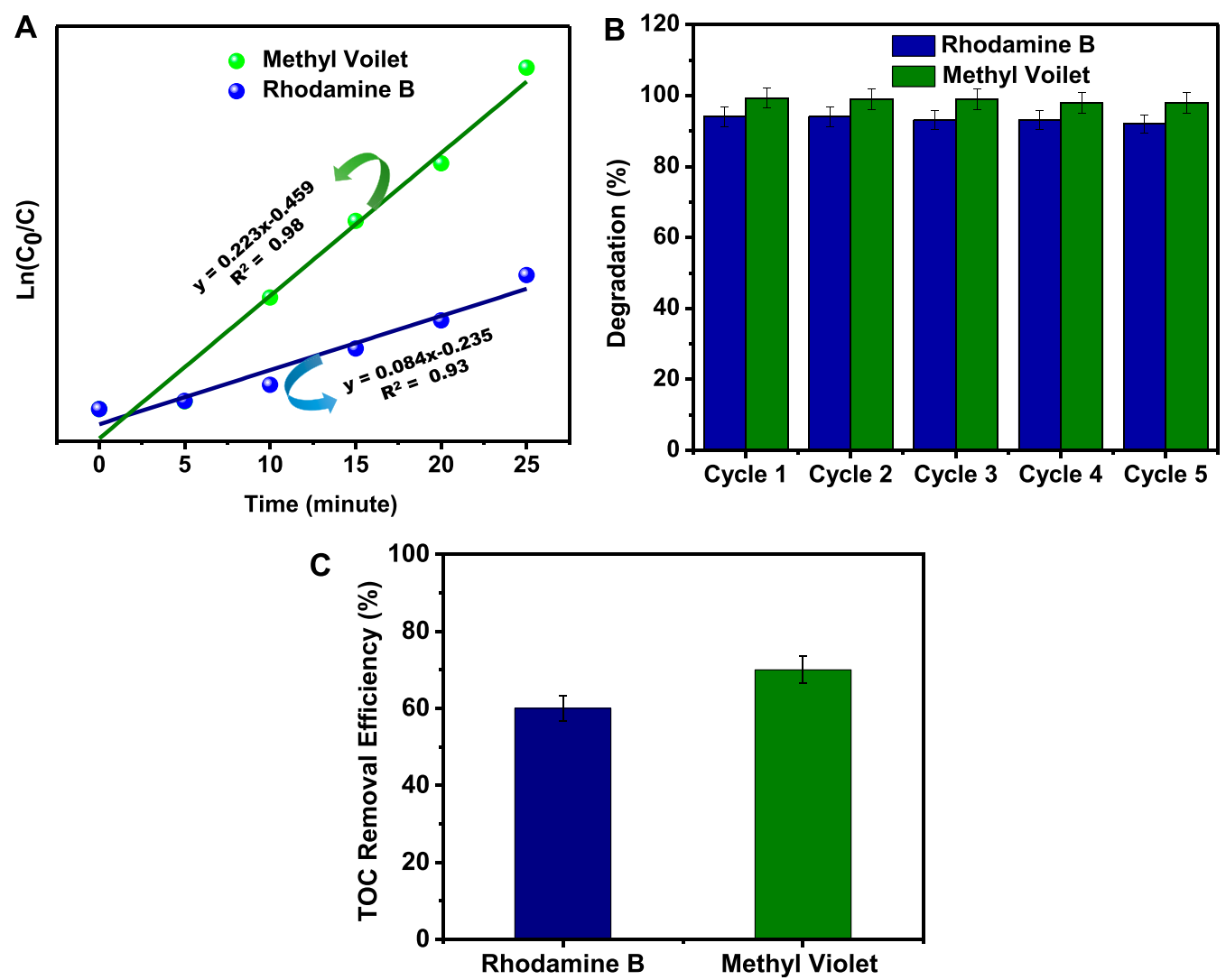

FIGURE 5 | (A) First-order kinetic fit plots. (B) Recyclability performance of Rh.B and M.V. (C) Total organic carbon removal ratio of Rh.B and M.V using SnS 2 NSs under visible light irradiation.

which provides an ample amount of surface adsorption sites, and a relatively large pore size might suggest the diffusion of organic dyes.

\section{Cell Viability Performance}

The biocompatibility of the $\mathrm{SnS}_{2}$ NSs was evaluated using MTT assay. In this assay, the metabolic activity of the cells was measured and correlated with the number of viable cells. The results of cell viability are shown in Figure 3, which suggests that $\mathrm{SnS}_{2}$ NSs do not exert obvious toxicity even at a very high concentration of $400 \mu \mathrm{g} / \mathrm{ml}$ (cell viability 90\%), but at higher concentrations (800 and 1,000 $\mu \mathrm{g} /$ $\mathrm{ml}(46.22$ and $26.45 \%)$ ) significant toxicity was observed. Wang et al. (2020) reported that a hydrothermally synthesized $\mathrm{SnS}_{2}$ nanostructures shows good biocompatibility and use for photothermal therapy. Another study conducted by Feng et al. (2020) has developed a Cedoped $\mathrm{SnO}_{2} / \mathrm{SnS}_{2}$-based photoelectrochemical cytosensor for recognition of tumor-associated macrophages. These studies significantly confirmed that $\mathrm{SnS}_{2}$-based materials have low toxicity and excellent biocompatibility for aquatic ecosystems.

\section{Photocatalytic Activity}

The photocatalytic activity of as-synthesized $\mathrm{SnS}_{2}$ NSs showed remarkable properties, such as adsorption of targeted organic pollutants, photoabsorption within a given light energy region, and the separation and transporting rate of the photogenerated electrons and holes in the photocatalyst.
The absorbance spectra of M.V and Rh.B are shown in Figure 4. The sequential change of the UV-Vis absorption spectra of M.V and Rh.B under visible light irradiation in regular time intervals are shown in Figures 4A,B. The photocatalytic degradation was recorded at wavelengths of 584 and $554 \mathrm{~nm}$ for M.V and Rh.B, respectively. Remarkably, it was found that, with increasing visible light time exposure, the absorption intensity continuously decreased in the presence of as-synthesized $\mathrm{SnS}_{2} \mathrm{NSs}$. The degradation efficiency or removal efficiency of organic dyes was estimated by the following equation:

$$
\text { Degradation efficency }(\%)=\frac{C-C_{0}}{C_{0}} * 100
$$

where $C$ and $C_{0}$ are dye concentrations after and before exposure to visible light irradiation, respectively.

The relative concentration of organic dyes such as M.V and Rh.B has been analyzed in the absence and presence of visible light irradiation using $\mathrm{SnS}_{2}$ NSs, as shown in Figure 4C. The degradation histogram, as shown in Figure 4D, reveals that the organic dyes such as M.V and Rh.B are degraded up to 99.6 and $94.0 \%$, respectively, in 25 min under visible light irradiation. However, in the absence of visible light irradiation, the degradation rate of Rh.B and M.V was almost negligible. 

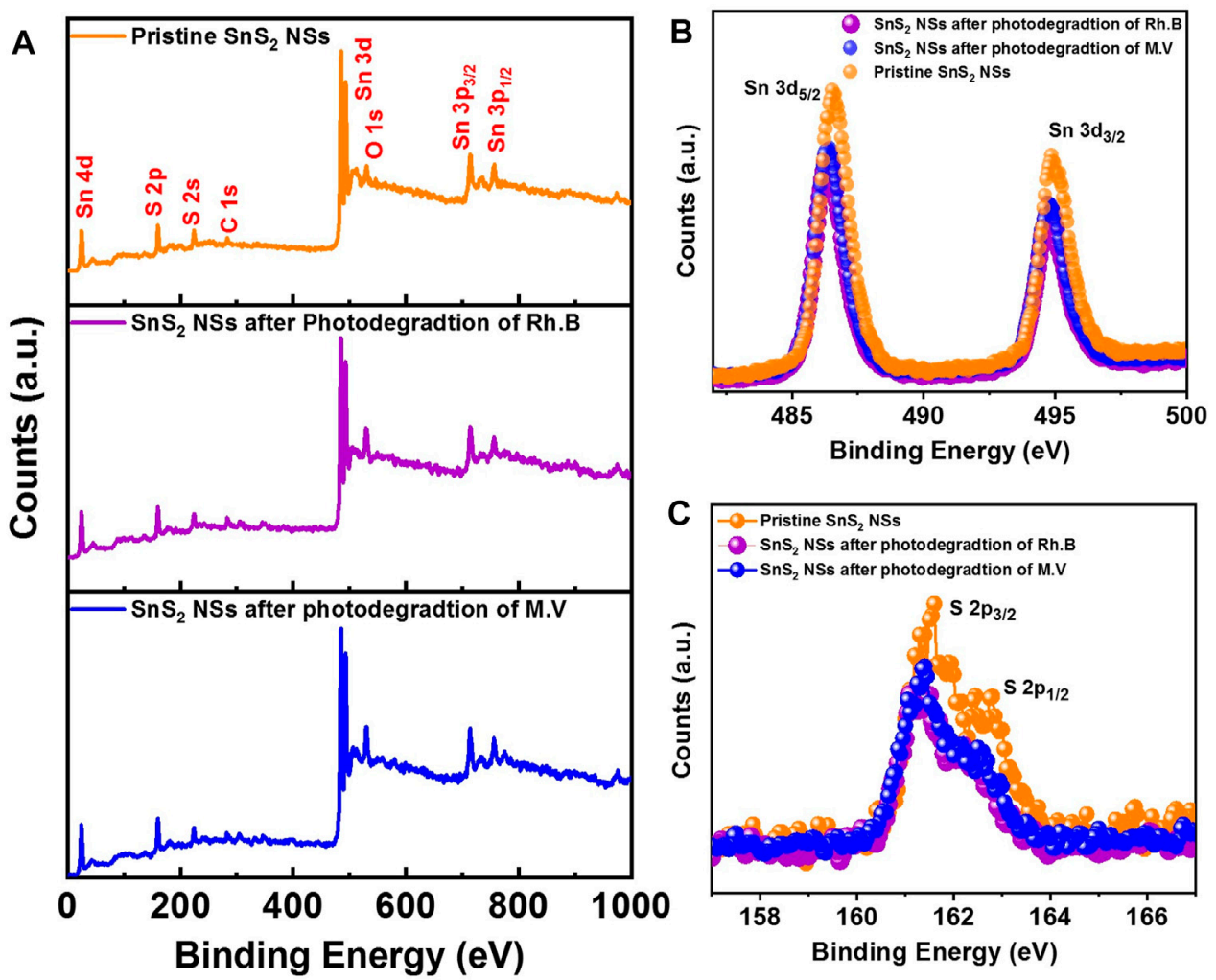

FIGURE 6 | XPS spectrum of $\mathrm{SnS}_{2}$ NSs before and after photodegradation of Rh.B and M.V. (A) Survey spectra. (B) Sn 3d spectra. (C) S 2p spectra.

TABLE 1 | Comparison between the photocatalytic activities of as-synthesized $\mathrm{SnS}_{2} \mathrm{NSs}$ with other decorated/undecorated semiconducting SnS ${ }_{2}$-based photocatalysts.

\begin{tabular}{|c|c|c|c|c|c|c|c|c|}
\hline $\begin{array}{l}\text { Sample } \\
\text { no. }\end{array}$ & Photocatalyst & $\begin{array}{l}\text { Time } \\
\text { (in min) }\end{array}$ & $\begin{array}{l}\text { Light } \\
\text { source }\end{array}$ & Dye used & $\begin{array}{l}\text { Catalyst } \\
\text { dose ratio }\end{array}$ & $\begin{array}{c}\text { Dye } \\
\text { concentration }\end{array}$ & $\begin{array}{l}\text { Degradation } \\
\text { efficiency (\%) }\end{array}$ & Reference \\
\hline 1 & $\mathrm{SnS}_{2}-\mathrm{CdS}$ & 30 & UV light & Methyl orange & $20 \mathrm{mg} / 50 \mathrm{ml}$ & $6.0 \times 10^{-5} \mathrm{~mol} / \mathrm{L}$ & 99.0 & Li et al. (2012a) \\
\hline 2 & $\mathrm{SnS}_{2} / \mathrm{RGO}$ & $\begin{array}{l}140 \\
97\end{array}$ & $\begin{array}{l}\text { Visible } \\
\text { light }\end{array}$ & $\begin{array}{l}\text { Remazol brilliant red and } \\
\text { Remazol brilliant blue }\end{array}$ & $2 \mathrm{mg} / 10 \mathrm{ml}$ & 10 ppm & 99.7 & $\begin{array}{l}\text { Dashairya et al. } \\
\text { (2018) }\end{array}$ \\
\hline 3 & $\begin{array}{l}\mathrm{SnS}_{2}-\mathrm{SiO}_{2} @ \\
\alpha-\mathrm{Fe}_{2} \mathrm{O}_{3}\end{array}$ & 100 & $\begin{array}{l}\text { Visible } \\
\text { light }\end{array}$ & Methyl blue & $40 \mathrm{mg} / 100 \mathrm{ml}$ & 5 ppm & 96.0 & Balu et al. (2018) \\
\hline 4 & $\begin{array}{l}\mathrm{SnO}_{2} \text { decorated } \\
\mathrm{SnS}_{2}\end{array}$ & 45 & $\begin{array}{l}\text { Visible } \\
\text { light }\end{array}$ & Methyl orange & $50 \mathrm{mg} / 50 \mathrm{ml}$ & 10 ppm & 97 & $\begin{array}{l}\text { Zhou et al. } \\
\text { (2012) }\end{array}$ \\
\hline 5 & $\mathrm{SnS}_{2}$ nanoflakes & 120 & $\begin{array}{l}\text { Visible } \\
\text { light }\end{array}$ & Rhodamine B & $\begin{array}{c}150 \mathrm{mg} / \\
150 \mathrm{ml}\end{array}$ & 10 ppm & 61 & $\begin{array}{l}\text { Umar et al. } \\
(2013)\end{array}$ \\
\hline 6 & $\begin{array}{l}\mathrm{SnS}_{2} \\
\text { nanostructures }\end{array}$ & 25 & $\begin{array}{l}\text { Visible } \\
\text { light }\end{array}$ & $\begin{array}{l}\text { Rhodamine B } \\
\text { Methyl violet }\end{array}$ & $5 \mathrm{mg} / 10 \mathrm{ml}$ & 10 ppm & $\begin{array}{l}94.0 \\
99.6\end{array}$ & Present work \\
\hline
\end{tabular}

The behavior of photocatalytic activity is a tedious process that is driven by many parameters such as temperature, light intensity, catalyst loading, and concentration of organic pollutants. The photocatalytic kinetic behavior of $\mathrm{SnS}_{2} \mathrm{NSs}$ has been obtained from the Langmuir-Henshelwood model. The catalytic decomposition was estimated by using a pseudo-first-order reaction kinetics equation which is given by:

$$
\ln \left(\frac{C_{0}}{C}\right)=k t
$$

where $C_{0}, C, k$, and $t$ are initial concentration, varying concentration, kinetic constant, and time, respectively. Figure 5A shows the kinetic rate constant $(k)$ for the initial concentrations of M.V and Rh.B. The first-order reaction kinetic rate constant is 0.2236 and $0.0845 \mathrm{~min}^{-1}$ for M.V and Rh.B, respectively.

Stability and reusability play a vital role in the valuation of photocatalyst life cycle because photoanodic corrosion restricts their stability. To identify the stability and the reusability property of $\mathrm{SnS}_{2} \mathrm{NSs}$, the degradation process has been performed up to 


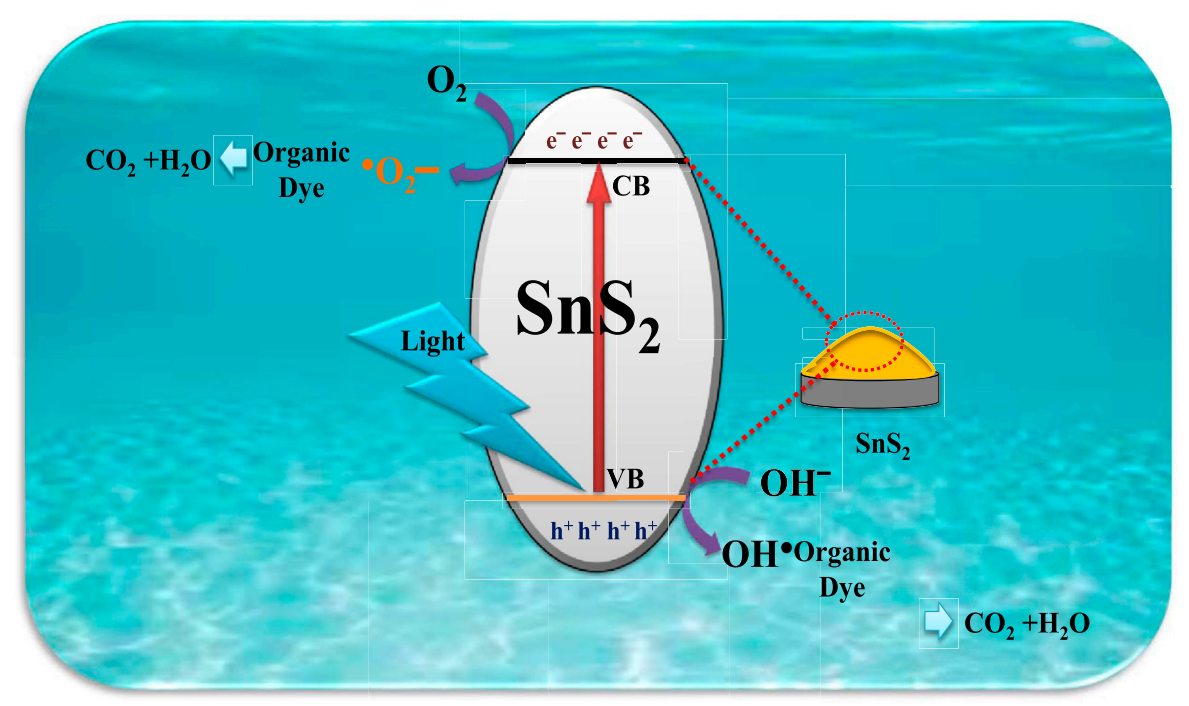

SCHEME 3 | Schematic illustration of the degradation mechanism of organic dyes over the surface of SnS $\mathrm{NSs}_{2}$

five times. In every cycle, $\mathrm{SnS}_{2} \mathrm{NSs}$ were reused for their photocatalytic activity by using the separation and centrifuge method. A histogram graph has been plotted between the degradation efficiency of dye removal and the number of cycles, as shown in Figure 5B. In the first cycle, it has been observed that the photodegradation of aqueous solution of M.V and Rh.B has been degraded up to $\sim 99.6$ and $\sim 94.0 \%$, respectively. After performing this experiment, it has been found that the degradation efficiency is $\sim 91$ and $\sim 97 \%$, respectively, for Rh.B and M.V at the fifth cycle, which reveals the excellent stability and recyclability properties of $\mathrm{SnS}_{2} \mathrm{NSs}$.

The mineralization capability of photocatalysts is also an important criterion to evaluate their photocatalytic efficiency. Thus, the TOC removal efficiency of Rh.B and M.V by $\mathrm{SnS}_{2} \mathrm{NSs}$ was investigated using a TOC analyzer. In Figure 5C, the TOC removal ratio of Rh.B and M.V reached $\sim 60$ and $\sim 70 \%$ using $\mathrm{SnS}_{2}$ NSs under visible light irradiation in $25 \mathrm{~min}$, respectively. These findings demonstrate that $\mathrm{SnS}_{2} \mathrm{NSs}$ can easily mineralize Rh.B and M.V during the photocatalytic process and could be effectively mineralized into residual organic molecules, indicating their high potential for practical applications.

XPS was performed to determine the distribution of elements and compositional states on the surface of the sample. The XPS spectra of as-synthesized $\mathrm{SnS}_{2}$ NSs were investigated before and after the photocatalytic degradation of Rhodamine $\mathrm{B}$ and methyl violet after five successive cycles, as shown in Figure 6. The XPS survey spectrum $(0-1,000 \mathrm{eV})$ evidences the presence of $\mathrm{C}, \mathrm{O}, \mathrm{Sn}$, and $\mathrm{S}$ elements, as shown in Figure 6A. In Figures 6B,C, the XPS pattern of $\mathrm{Sn} 3 \mathrm{~d}$ in pristine $\mathrm{SnS}_{2} \mathrm{NSs}$ shows two prominent peaks at 486.4 and $494.8 \mathrm{eV}$, which correspond to $\mathrm{Sn} 3 \mathrm{~d}_{5 / 2}$ and $S n 3 \mathrm{~d}_{3 / 2}$, respectively. The XPS spectra of $\mathrm{S} 2 \mathrm{p}$ in bare $\mathrm{SnS}_{2}$ NSs reveal two peaks at 161.4 and $162.4 \mathrm{eV}$, which correspond to $\mathrm{S} 2 \mathrm{p}_{3 / 2}$ and $\mathrm{S} 2 \mathrm{p}_{1 / 2}$, respectively ( $\mathrm{Hu}$ et al., 2013). After the photodegradation of Rhodamine B and methyl violet, the Sn $3 \mathrm{~d}$ and S $2 \mathrm{p}$ peaks of
$\mathrm{SnS}_{2}$ NSs are slightly shifted to a lower binding energy $(\sim 0.2 \mathrm{eV})$ compared to the pristine $\mathrm{SnS}_{2} \mathrm{NSs}$. This might be attributed to the photoreduction of $\mathrm{SnS}_{2}$ NSs that occurred on the surface throughout the photodegradation process, confirming the high stability and sustainability of the photocatalyst (Shi et al., 2010; Zhai et al., 2017).

Among various $2 \mathrm{D} \mathrm{SnS}_{2}$-based nanostructured materials, the as-synthesized $\mathrm{SnS}_{2} \mathrm{NS}$ s revealed a highly efficient photocatalytic activity for organic pollutants such as Rh.B and M.V under visible-light-driven irradiation, as shown in Table $\mathbf{1 .}$

\section{Photocatalytic Mechanism}

The main advantages of the photocatalytic activity of semiconductor catalysts are the photoabsorption ability within the given light regime and the separation and transfer of photogenerated electrons and holes in themselves. Under visible light irradiation, the degradation of organic dyes such as Rh. B and M.V over the surface of as-synthesized semiconducting $\mathrm{SnS}_{2} \mathrm{NSs}$ has been demonstrated by a schematic, as shown in Scheme 3.

A narrow bandgap semiconductor catalyst allows more photons to get absorbed, resulting in excellent catalytic activity under visible light irradiation. In the photocatalytic mechanism, a photocatalyst directly attacks the chromophore of organic pollutants due to the weak interaction between the photocatalyst and the dye (Saison et al., 2011). Due to the highly reactive free radicals in the photocatalytic degradation process, all contaminants break into inorganic substances or small molecules through the addition reaction, substitution reaction, and the electron transfer between free radicals and organic pollutants.

The generation of electron-hole pairs and the excitation of valence band electron will take place under visible light irradiation. The excited electron from the valence band will further transfer the electron to the conduction band, which results in the generation of $\mathrm{e}^{-} / \mathrm{h}^{+}$pairs. The holes from the valence band of assynthesized $\mathrm{SnS}_{2}$ NSs react with hydroxyl groups by breaking the water molecules and form highly reactive hydroxyl radicals $\left({ }^{\circ} \mathrm{OH}\right)$, 
and the electron from the conduction band reacts with the oxygen molecules attached over the surface of $\mathrm{SnS}_{2} \mathrm{NSs}$ and forms superoxide anion radicals $\left({ }^{\bullet} \mathrm{O}_{2}{ }^{-}\right)$. Furthermore, these ${ }^{\bullet} \mathrm{O}^{2-}$ react with $\mathrm{H}^{+}$and produce $\mathrm{H}_{2} \mathrm{O}_{2}$, and finally this $\mathrm{H}_{2} \mathrm{O}_{2}$ deteriorates into hydroxyl radicals $\left({ }^{\circ} \mathrm{OH}\right)$ (Cao et al., 2017).

The plausible photocatalytic degradation mechanism for the catalytic behavior of as-synthesized semiconductor $\mathrm{SnS}_{2} \mathrm{NSs}$ was suggested by the given equations as follows:

$$
\begin{gathered}
\mathrm{SnS}_{2}+\mathrm{hv} \rightarrow \mathrm{h}^{+}(\mathrm{VB})+\mathrm{e}^{-}(\mathrm{CB}) \\
\mathrm{H}_{2} \mathrm{O} \rightarrow \mathrm{H}^{+}+\mathrm{OH}^{-} \\
\mathrm{O}_{2}+\mathrm{e}^{-} \rightarrow \mathrm{O}_{2}^{-} \\
\mathrm{O}_{2}^{-}+\mathrm{H}^{+} \rightarrow \mathrm{H}_{2} \mathrm{O}_{2} \\
\mathrm{H}_{2} \mathrm{O}_{2} \rightarrow \mathrm{OH}^{-} \\
\mathrm{OH}^{-}+\mathrm{h}^{+} \rightarrow \mathrm{OH}^{-}
\end{gathered}
$$

Dye $+\mathrm{OH} \rightarrow$ dye $\rightarrow$ degradation products $\left(\mathrm{CO}_{2} / \mathrm{H}_{2} \mathrm{O}\right)$

In general, highly reactive oxyradicals such as hydroxyl $\left(\mathrm{OH}^{\bullet}\right)$ and superoxide anion $\left(\mathrm{O}_{2}{ }^{--}\right)$are responsible for the degradation of organic dyes such as Rh.B and M.V in the presence of visible light irradiation. However, at room temperature, the hydroxyl group $\left(\mathrm{OH}^{\bullet}\right)$ plays a vital role in the degradation of organic dyes with a simple magnetic stirring process. These highly reactive oxyradicals are formed over the surface of an as-synthesized $\mathrm{SnS}_{2}$ catalyst by the separation of electron-hole $\left(\mathrm{e}^{-} / \mathrm{h}^{+}\right)$pairs (Umar et al.). Organic dyes react with the hydroxyl groups $\left(\mathrm{OH}^{\bullet}\right)$ and superoxide anion $\left(\mathrm{O}_{2}{ }^{--}\right)$, break into smaller molecules, and generate intermediates, such as $\mathrm{CO}_{2}, \mathrm{H}_{2} \mathrm{O}$, etc. Finally, under visible light irradiation, the transformation or oxidation of harmful organic dyes into less harmful chemicals takes place.

\section{CONCLUSION}

In summary, $\mathrm{SnS}_{2} \mathrm{NSs}$ have been synthesized successfully using the facile single-step bottom-up hydrothermal method. The obtained $\mathrm{SnS}_{2}$ NSs have a low bandgap $(\sim 1.6 \mathrm{eV})$, a high surface area $\left(56 \mathrm{~m}^{2} / \mathrm{g}\right)$, and an anionic nature, resulting in an efficient photocatalyst for the degradation of organic dyes. The as-synthesized $\mathrm{SnS}_{2}$ NSs have been used for the removal of organic dyes such as Rh.B and M.V. SnS 2 NSs exhibited good degradation efficiency for Rh.B (94\%) and M.V (99.6\%) in $25 \mathrm{~min}$. The kinetic rate constant for Rh.B and M.V was calculated by using the first-order Langmuir-Hinshelwood model. The recyclability test suggests the excellent stability of the photocatalyst for up to five cycles. The XPS spectrum of $\mathrm{SnS}_{2}$

\section{REFERENCES}

Balu, S., Uma, K., Pan, G.-T., Yang, T., and Ramaraj, S. (2018). Degradation of Methylene Blue Dye in the Presence of Visible Light Using SiO2@a-Fe2O3 Nanocomposites Deposited on SnS2 Flowers. Materials 11, 1030. doi:10.3390/ ma11061030

Brillas, E., and Martínez-Huitle, C. A. (2015). Decontamination of Wastewaters Containing Synthetic Organic Dyes by Electrochemical Methods. An Updated
NSs was investigated before and after the photodegradation of Rhodamine B and Methyl Violet, suggesting the high stability of the photocatalyst. Herein we have also discussed the detailed degradation mechanism for the removal of dyes, which suggests the formation of a large number of oxyradicals and enhanced photocatalytic performance of as-synthesized $\mathrm{SnS}_{2}$ NSs. Moreover, in vitro cytotoxicity was also evaluated against human cervical cancer cell lines (HeLa cells) with different concentrations $(0-1,000 \mu \mathrm{g} / \mathrm{ml})$ of as-synthesized $\mathrm{SnS}_{2} \mathrm{NSs}$. In the present investigations, we believed that this highly responsive photocatalyst opened a new avenue for the degradation of environmental pollutants by the modification of the energy bandgap and charge nature on the photocatalyst surface.

\section{DATA AVAILABILITY STATEMENT}

The raw data supporting the conclusion of this article will be made available by the authors, without undue reservation.

\section{AUTHOR CONTRIBUTIONS}

RS and AS conceived the idea of $2 \mathrm{D} \mathrm{SnS}_{2}$ nanostructure-based photocatalytic degradation. RS carried out the whole experiments, analyzed the data, and wrote the draft of the manuscript. PK and SR helped to do photocatalytic experiments. SU discussed all experiment results. UY and PS also contributed to testing in-vitro cytotoxicity of $2 \mathrm{D} \mathrm{SnS}_{2}$ nanostructures and to preparing a robotic model. SU given scientific suggestions and comments on the manuscript. AS supervised the research at all stages and led all groups. All the authors discussed the results and commented on the manuscript.

\section{ACKNOWLEDGMENTS}

RS is thankful to UGC for providing fellowship. AS is thankful to DST India (DST-PURSE Scheme 5050), DST-SERB (EMR/2016/ 007720), and research grant for faculty (IoE Scheme) under Development Scheme No.: 6031 for providing financial assistance. AS is also thankful to the Department of Physics, $\mathrm{BHU}$, for providing financial assistance under CAS scheme. The authors are also thankful to the University Science Instrumentation Center (USIC Level II) and the Department of Botany, Institute of Science, Banaras Hindu University, Varanasi, India, for UV-vis and TOC measurements, respectively.

Review. Appl. Catal. B: Environ. 166-167, 603-643. doi:10.1016/ j.apcatb.2014.11.016

Cao, S., Low, J., Yu, J., and Jaroniec, M. (2015). Polymeric Photocatalysts Based on Graphitic Carbon Nitride. Adv. Mater. 27, 2150-2176. doi:10.1002/ adma.201500033

Cao, Y., Li, Q., and Wang, W. 2017, Undefined Construction of a Crossed-LayerStructure MoS2/gC3 N4 Heterojunction with Enhanced Photocatalytic Performance. Available at: https://pubs.rsc.org/-/content/articlehtml/2017/ra/ c6ra26925g (Accessed May 12, 2021). 
Dashairya, L., Sharma, M., Basu, S., and Saha, P. (2019). SnS2/RGO Based Nanocomposite for Efficient Photocatalytic Degradation of Toxic Industrial Dyes under Visible-Light Irradiation. J. Alloys Comp. 774, 625-636. doi:10.1016/j.jallcom.2018.10.008

Bharatula, L. D., Erande, M. B., Mulla, I. S., Rout, C. S., and Late, D. J. (2016). SnS2nanoflakes for Efficient Humidity and Alcohol Sensing at Room Temperature. RSC Adv. 6, 105421-105427. doi:10.1039/c6ra21252b

Du, Y., Yin, Z., Rui, X., Zeng, Z., Wu, X., Liu, J., et al. (2013). A Facile, Relative green, and Inexpensive Synthetic Approach Toward Large-Scale Production of SnS 2 Nanoplates for High-Performance Lithium-Ion Batteries. Nanoscale 5 (4), 1456-1459. doi:10.1039/c2nr33458e

Feng, R., Tian, K., Zhang, Y., Liu, W., Fang, J., Khan, M. S., et al. (2020). Recognition of M2 Type Tumor-Associated Macrophages with Ultrasensitive and Biocompatible Photoelectrochemical Cytosensor Based on Ce Doped SnO2/SnS2 Nano Heterostructure. Biosens. Bioelectron. 165, 112367. doi:10.1016/j.bios.2020.112367

Guo, Y., Wang, L., Yang, L., Zhang, J., Jiang, L., and Ma, X. (2011). Optical and Photocatalytic Properties of Arginine-Stabilized Cadmium Sulfide Quantum Dots. Mater. Lett. 65, 486-489. doi:10.1016/j.matlet.2010.10.057

Han, S., Liu, K., Hu, L., Teng, F., Yu, P., and Zhu, Y. (2017). Superior Adsorption and Regenerable Dye Adsorbent Based on Flower-Like Molybdenum Disulfide Nanostructure. Sci. Rep. 7, 1-11. doi:10.1038/srep43599

Hu, X., Song, G., Li, W., Peng, Y., Jiang, L., Xue, Y., et al. (2013). Phase-Controlled Synthesis and Photocatalytic Properties of SnS, SnS2 and SnS/SnS2 Heterostructure Nanocrystals. Mater. Res. Bull. 48, 2325-2332. doi:10.1016/ j.materresbull.2013.02.082

Kim, S., Choi, M., and Bulletin, H. C.-M. R. (2016). Undefined Photocatalytic Activity of SnO2 Nanoparticles in Methylene Blue Degradation. Available at: https://www.sciencedirect.com/science/article/pii/S0025540815301586 (Accessed May 12, 2021).

Li, S., Chen, J., Hu, S., Wang, H., Jiang, W., and Chen, X. (2020a). Facile Construction of Novel Bi2WO6/Ta3N5 Z-Scheme Heterojunction Nanofibers for Efficient Degradation of Harmful Pharmaceutical Pollutants. Chem. Eng. J. 402, 126165. doi:10.1016/j.cej.2020.126165

Li, S., Hu, S., Jiang, W., Zhang, J., Xu, K., and Wang, Z. (2019). In Situ construction of WO3 Nanoparticles Decorated Bi2MoO6 Microspheres for Boosting Photocatalytic Degradation of Refractory Pollutants. J. Colloid Interf. Sci. 556, 335-344. doi:10.1016/j.jcis.2019.08.077

Li, S., Wang, C., Liu, Y., Xue, B., Jiang, W., Liu, Y., et al. (2021). Photocatalytic Degradation of Antibiotics Using a Novel Ag/Ag2S/Bi2MoO6 Plasmonic p-n Heterojunction Photocatalyst: Mineralization Activity, Degradation Pathways and Boosted Charge Separation Mechanism. Chem. Eng. J. 415, 128991. doi:10.1016/j.cej.2021.128991

Li, S., Xue, B., Chen, J., Jiang, W., and Liu, Y. (2020b). Nanoparticles as Highly Efficient Photocatalyst for the Treatment of Toxic Wastewater. Catalysts 1-15.

Li, X., Zhu, J., and Li, H. (2012b). Comparative Study on the Mechanism in Photocatalytic Degradation of Different-type Organic Dyes on SnS2 and CdS. Appl. Catal. B: Environ. 123-124, 174-181. doi:10.1016/j.apcatb.2012.04.009

Li, X., Zhu, J., and Li, H. (2012a). Undefined Comparative Study on the Mechanism in Photocatalytic Degradation of Different-Type Organic Dyes on SnS2 and CdS. Appl. Catal. B: Environ. 123-124, 174-181. doi:10.1016/ j.apcatb.2012.04.009

Lorenz, T., Joswig, J., and Seifert, G. (2014). Unefined Combined SnS@ SnS2 Double Layers: Charge Transfer and Electronic Structure. Available at: https:// iopscience.iop.org/article/10.1088/0268-1242/29/6/064006/meta (Accessed May 12, 2021).

Opoku, F., Govender, K. K., van Sittert, C. G. C. E., Govender, P. P., and Govender, P. P. (2017). Recent Progress in the Development of Semiconductor-Based Photocatalyst Materials for Applications in Photocatalytic Water Splitting and Degradation of Pollutants. Adv. Sust. Syst. 1, 1700006. doi:10.1002/ adsu. 201700006

Patil, S. S., and Shinde, V. M. (1988). Biodegradation Studies of Aniline and Nitrobenzene in Aniline Plant Wastewater by Gas Chromatography. Environ. Sci. Technol. 22, 1160-1165. doi:10.1021/es00175a005

Robinson, T., Mcmullan, G., Marchant, R., and Nigam, P. (2001). Remediation of Dyes in Textile Effluent: a Critical Review on Current Treatment Technologies with a Proposed Alternative. Bioresour. Tech. 77, 247-255. doi:10.1016/s09608524(00)00080-8
Saison, T., Chemin, N., Chanéac, C., Durupthy, O., Ruaux, V., Mariey, L., et al. (2011). Bi2O3, BiVO4, and Bi2WO6: Impact of Surface Properties on Photocatalytic Activity under Visible Light. J. Phys. Chem. C 115, 5657-5666. doi:10.1021/jp109134z

Schwarzenbach, R. P., Egli, T., Hofstetter, T. B., Von Gunten, U., and Wehrli, B. (2010). Global Water Pollution and Human Health. Annu. Rev. Environ. Resour. 35, 109-136. doi:10.1146/annurev-environ-100809-125342

Sharma, R., Khanuja, M., Sharma, S., Narayan, S., and Prakash, O. (2017). Undefined Reduced Band Gap \& Charge Recombination Rate in Se Doped a-Bi2O3 Leads to Enhanced Photoelectrochemical and Photocatalytic Performance: Theoretical \& Experimental Insight. Int. J. Hydrogen Energ. 42, 20638-20648. doi:10.1016/j.ijhydene.2017.07.011

Shi, R., Lin, J., Wang, Y., Xu, J., and Zhu, Y. (2010). Visible-Light Photocatalytic Degradation of $\mathrm{BiTaO} 4$ Photocatalyst and Mechanism of Photocorrosion Suppression. J. Phys. Chem. C 114, 6472-6477. doi:10.1021/jp9101866

Singh, S., Pendurthi, R., Khanuja, M., Islam, S. S., Rajput, S., and Shivaprasad, S. M. (2017). Copper-doped Modified ZnO Nanorods to Tailor its Light Assisted Charge Transfer Reactions Exploited for Photo-Electrochemical and PhotoCatalytic Application in Environmental Remediation. Appl. Phys. A. 123, 184. doi:10.1007/s00339-017-0806-8

Song, H. S., Li, S. L., Gao, L., Xu, Y., Ueno, K., Tang, J., et al. (2013). HighPerformance Top-Gated Monolayer SnS2 Field-Effect Transistors and Their Integrated Logic Circuits. Nanoscale 5, 9666. doi:10.1039/c3nr01899g

Srivastava, R., Mishra, H., Singh, V., Vijay, K., Vikram, K. S., and Rajesh Kumar, S. (2019). Undefined pH Dependent Luminescence Switching of Tin Disulfide Quantum Dots. Available at: https://www.sciencedirect. com/science/article/pii/S0022231318322038?casa_token=veV8EeAPRBwAAAAA: Lc6w61aIaLsL1Y6Vi4FkA8NxqkP_CLUgE9Z3jv22mh5g9t1 Mk5q2mnrPRd2JQ0jP0K4CNhFjA (Accessed May 12, 2021).

Štengl, V., Bakardjieva, S., Grygar, T. M., Bludská, J., and Kormunda, M. (2013). TiO2-graphene Oxide Nanocomposite as Advanced Photocatalytic Materials. Chem. Cent. J. 7. doi:10.1186/1752-153X-7-41

Stock, N. L., Peller, J., Vinodgopal, K., and Kamat, P. V. (2000). Combinative Sonolysis and Photocatalysis for Textile Dye Degradation. Environ. Sci. Technol. 34, 1747-1750. doi:10.1021/es991231c

Su, G., Hadjiev, V. G., Loya, P. E., Zhang, J., Lei, S., Maharjan, S., et al. (2015). Chemical Vapor Deposition of Thin Crystals of Layered Semiconductor Sns2 for Fast Photodetection Application. Nano Lett. 15, 506-513. doi:10.1021/ nl503857r

Talebian, N., and Nilforoushan, M. R. (2010). Comparative Study of the Structural, Optical and Photocatalytic Properties of Semiconductor Metal Oxides toward Degradation of Methylene Blue. Thin Solid Films 518, 2210-2215. doi:10.1016/ j.tsf.2009.07.135

Tan, F., Qu, S., Wu, J., Liu, K., Zhou, S., and Wang, Z. (2011). Preparation of Sns2 Colloidal Quantum Dots and Their Application in Organic/inorganic Hybrid Solar Cells. Nanoscale Res. Lett. 6, 298. doi:10.1186/1556-276X-6-298

Tian, H., Wan, C., Xue, X., Hu, X., and Wang, X. (2017). Effective Electron Transfer Pathway of the Ternary TiO2/RGO/Ag Nanocomposite with Enhanced Photocatalytic Activity under Visible Light. Catalysts 7, 156. doi:10.3390/catal7050156

Umar, A., Akhtar, M., Dar, G., Abaker, M., Hajry, A., Baskoutas, S., et al. (2013). Undefined Visible-Light-Driven Photocatalytic and Chemical Sensing Properties of SnS2 Nanoflakes. Available at: https://www. sciencedirect.com/science/article/pii/S0039914013001999? casa_token=vcL6JhbVtYAAAAA:SahhMoWDddEeDRI7tELKMAdz-sYBCZlaQGHpzp8rdIvB65ZFm1 upZsf79ENsl0Ph6ESpP1cNw (Accessed May 12, 2021).

Wang, D., Tang, M., Jiang, H., Li, M., Jiang, S., Sun, L., et al. (2020). Helical Bowl-Like SnS2 with Structure-Induced Conversion Efficiency for Enhanced Photothermal Therapy. Chem. Eng. J. 400, 125814. doi:10.1016/j.cej.2020.125814

Xie, Y., Ali, G., Yoo, S. H., and Cho, S. O. (2010). Sonication-assisted Synthesis of CdS Quantum-Dot-Sensitized $\mathrm{TiO} 2$ Nanotube Arrays with Enhanced Photoelectrochemical and Photocatalytic Activity. ACS Appl. Mater. Inter. 2, 2910-2914. doi:10.1021/am100605a

Xie, Y., Chen, F., He, J., Zhao, J., and Hui, W. (2000). Undefined Photoassisted Degradation of Dyes in the Presence of $\mathrm{Fe} 3+$ and $\mathrm{H} 2 \mathrm{O} 2$ Under Visible Irradiation. Available at: https://www.sciencedirect.com/science/article/ pii/S1010603000003415?casa_token=z0HD7IXPPjIAAAAA:z-cYwzyNKJTiJWIKq11Nxju 7wmq1rTIcs-5WY6yFZVzf5 glCqnsLKLvZ7 6RE5E27tTDiAUaw (Accessed May 12, 2021). 
Zhai, H., Qi, J., Zhang, X., Li, H., Yang, L., Hu, C., et al. (2017). Preparation and Photocatalytic Performance of Hollow Structure LiNb3O8 Photocatalysts. Nanoscale Res. Lett. 12, 519. doi:10.1186/s11671-017-2291-6

Zhang, Y., Du, Z., Li, K., and Zhang, M. 2011, Undefined Size-Controlled Hydrothermal Synthesis of SnS2 Nanoparticles with High Performance in Visible Light-Driven Photocatalytic Degradation of Aqueous Methyl Orange. Sep. Purif. Tech. 81(1), 101-107. doi:10.1016/j.seppur.2011.07.016

Zhang, Y. C., Li, J., Zhang, M., and Dionysiou, D. D. (2011a). Size-Tunable Hydrothermal Synthesis of SnS2Nanocrystals with High Performance in Visible Light-Driven Photocatalytic Reduction of Aqueous $\mathrm{Cr}(\mathrm{VI})$. Environ. Sci. Technol. 45, 9324-9331. doi:10.1021/es202012b

Zhang, Y. C., Li, J., Zhang, M., and Dionysiou, D. D. (2011b). Size-Tunable Hydrothermal Synthesis of SnS2 Nanocrystals with High Performance in Visible Light-Driven Photocatalytic Reduction of Aqueous Cr(VI). Environ. Sci. Technol. 45, 9324-9331. doi:10.1021/es202012b

Zhong, H. E., Shaogui, Y., Yongming, J. U., and Cheng, S. (2009). Microwave Photocatalytic Degradation of Rhodamine B Using TiO2 Supported on Activated Carbon: Mechanism Implication. J. Environ. Sci. 21, 268-272. doi:10.1016/S1001-0742(08)62262-7

Zhou, X., Zhou, T., Hu, J., and Li, J. (2012). Controlled Strategy to Synthesize SnO2 Decorated SnS2 Nanosheets with Enhanced Visible Light Photocatalytic Activity. CrystEngComm 14, 5627. doi:10.1039/c2ce25309g
Zhu, H., Fu, Y., Jiang, R., Yao, J., Liu, L., and Chen, Y. (2013). Preparation, Characterization and Adsorption Properties of Chitosan Modified Magnetic Graphitized Multi-Walled Carbon Nanotubes for Highly Effective Removal. Appl. Surf. Sci. 285, 865-873. doi:10.1016/j.apsusc.2013.09.003

Conflict of Interest: The authors declare that the research was conducted in the absence of any commercial or financial relationships that could be construed as a potential conflict of interest.

Publisher's Note: All claims expressed in this article are solely those of the authors and do not necessarily represent those of their affiliated organizations, or those of the publisher, the editors and the reviewers. Any product that may be evaluated in this article, or claim that may be made by its manufacturer, is not guaranteed or endorsed by the publisher.

Copyright (C) 2021 Srivastava, Kumar Vishwakarma, Yadav, Rai, Umrao, Giri, Saxena and Srivastava. This is an open-access article distributed under the terms of the Creative Commons Attribution License (CC BY). The use, distribution or reproduction in other forums is permitted, provided the original author(s) and the copyright owner(s) are credited and that the original publication in this journal is cited, in accordance with accepted academic practice. No use, distribution or reproduction is permitted which does not comply with these terms. 